\title{
EFFECT OF WARM COMPRESS AND DEEP BREATHING EXERCISE ON THE REDUCTION OF PRIMARY DYSMENORRHEA
}

\author{
Precilia Mustika Dini Kharisma, Wahyuni \\ Study Program of Physiotherapy, Universitas Muhammadiyah, Surakarta
}

\begin{abstract}
Background: Dysmenorrhea is an important health problem. There is a wide variation in the estimate of dysmenorrhea from studies around the world reporting a range between $28 \%$ and $71.7 \%$. Primary dysmenorrhea is defined as painful menses in women with normal pelvic anatomy, usually beginning during adolescence.Dysmenorrhea is characterized by crampy pelvic pain beginning shortly before or at the onset of menses and lasting 1 to 3 days. This study aimed to determine the effect of warm compress and deep breathing exercise on the reduction of primary dysmenorrhea.

Subjects and Method: This was a quasi-experiment study before and after with no control design. A sample of 20 women of reproductive age was selected for this study. The dependent variable was dysmenorrhea. The independent variable was a pain therapy consisting of warm compress and deep breathing. The warm compress was given for 20 minutes using hot jar water with temperature $50^{\circ} \mathrm{C}$ to $60^{\circ} \mathrm{C}$. Deep breathing exercise was given for 10 minutes, with relaxed position of the study subjects. Deep breathing was performed simultaneously with the warm compress. Both interventions were given once on the first day of menstruation. Dysmenorrhea was measured by Numerical Rating Scale (NRS) with a $\mathrm{o}$ to 10 pain intensity numeric rating scale. The mean score of dysmenorrhea before and after the intervention was measured by paired t-test.

Results: Dysmenorrhea after warm compress and deep breathing exercise $($ Mean $=4.20 ; \mathrm{SD}=1.27)$ was lower than before $(M e a n=8.50 ; \mathrm{SD}=1.75)$, and it was statistically significant $(\mathrm{p}=0.002)$.

Conclusion: Warm compress and deep breathing exercise therapy is effective to alleviate primary dysmenorrhea.
\end{abstract}

Keywords: warm compress, deep breathing exercise, primary dysmenorrhea

\section{Correspondence:}

Wahyuni. Study Program of Physiotherapy, Universitas Muhammadiyah, Surakarta, Surakarta, Central Java. Email: wahyuni@ums.ac.id.

Mobile: 0813295518 